\title{
Uso de redes neurais artificiais e modelos de regressão para estimar volume de espécies nativas em Portel, Pará - Brasil
}

\section{Use of artificial neural networks and regression models to estimate volume of native species in Portel, Pará - Brazil}

\author{
Marcos Vinicius Cardoso-Silva ${ }^{1} \bullet$ Yasmim de Andrade-Ramos ${ }^{1} \bullet$ Mathaus Messias Coimbra-Limeira $^{2} \bullet$ \\ Maria Cristina Bueno-Coelho ${ }^{3}$. André Ferreira dos Santos ${ }^{3} \bullet$ Marcos Giongo $^{3} \bullet$ Mauro Luiz Erpen ${ }^{4}$
}

\begin{abstract}
The objective of the present study was to compare the volume estimates obtained by regression equations with artificial neural networks (RNA) for native areas under management plan in the Portel region, state of Pará, from the rigorous cubing data of 864 trees with $\mathrm{DBH} \geq 45 \mathrm{~cm}$ from Annual Production Units (UPA) managed in 2015 in an area of dense ombrophilous terra firme forest. The data processing aimed to select the best regression model considering the UPA 1. The best performing equation was chosen according to the root mean square error in percent (RQME\%), Pearson correlation and percentage residual graph. For the selection of the best network and its comparison with the best adjusted regression equation, the statistics used were: RQME\%, Pearson correlation between observed and estimated volume and bias. The best performing model was the Spurr $\left(V=\beta_{0}+\beta_{1}{ }^{*} \operatorname{dap}^{2} h\right)$, which was later compared with the best RNA obtained from data training. Both methods showed acceptable fit and precision statistics, with potential use to estimate the volume of the species. However, the RNA was higher showing higher precision in relation to the regression in volume estimation..
\end{abstract}

Key words: Artificial intelligence, rigorous cubing, individual trees, forest management.

\footnotetext{
1. Programa de Pós-Graduação em Ciências Florestais e Ambientais; Universidade Federal do Tocantins; Gurupi Tocantins; markuz@uft.edu.br; yasmimaramos@gmail.com

2. Graduação em Engenharia Florestal; Universidade Federal do Tocantins; Gurupi - Tocantins; mathauslimeira2010@gmail.com

3. Professor (a), Doutor (a) em Engenharia Florestal; Universidade Federal do Tocantins; Gurupi - Tocantins; mariacristina@uft.edu. br; andrefs@uft.edu.br; giongo@uft.edu.br

4. Professor, Doutorando em Engenharia Civil; Instituto Federal de Ciência e Tecnologia do Tocantins; Gurupi - Tocantins; mauro. luiz.erpen@gmail.com
}

Recibido: 02/09/2019 Aceptado: 18/11/2019

Publicado: 19/12/2019 DOI: $10.18845 / \mathrm{v} 17 \mathrm{i} 40.4901$ 


\section{Resumo}

O objetivo do presente estudo foi comparar as estimativas do volume obtidas por equações de regressão com redes neurais artificiais (RNA) para áreas nativas sob plano de manejo na região de Portel, estado do Pará, a partir dos dados de cubagem rigorosa de 864 árvores com DAP $\geq 45 \mathrm{~cm}$ de Unidades de Produção Anual (UPA) manejada em 2015 em área de floresta ombrófila densa de terra firme. O processamento dos dados visou selecionar o melhor modelo de regressão considerando a UPA 1. A equação com melhor desempenho foi escolhida de acordo com a raiz do erro quadrado médio em porcentagem (RQME\%), correlação de Pearson e gráfico de resíduos percentuais. Para a seleção da melhor rede e a sua respectiva comparação com a melhor equação de regressão ajustada, as estatísticas utilizadas foram: RQME\%, correlação de Pearson entre o volume observado e estimado e bias. $\mathrm{O}$ modelo com melhor desempenho foi o Spurr $\left(V=B_{0}+B_{1}{ }^{*}\right.$ dap' $\left.h\right)$ sendo posteriormente comparada com a melhor RNA obtida a partir do treinamento dos dados. Verificou-se que ambos os métodos apresentaram estatísticas de ajuste e precisão aceitáveis, com potencial utilização para estimar o volume da espécie. No entanto, a RNA mostrou-se superior evidenciando maior precisão em relação à regressão na estimativa de volume.

Palavras chave:Inteligência artificial, cubagem rigorosa, árvores individuais, manejo florestal.

\section{Introdução}

O manejo florestal consiste em administrar a obtenção de benefícios econômicos, sociais e ambientais, respeitando-se os mecanismos de sustentabilidade do ecossistema. O Brasil ocupa uma área de $8.514 .876 \mathrm{Km}^{2}$, sendo que $5.217 .423 \mathrm{~km}^{2}$, ou seja, corresponde a $61 \%$ do território brasileiro estão dentro da Amazônia Legal [1]. Está inserido nos quatro ecossistemas: cerrado, pantanal, floresta amazônica e área de transição, objeto do manejo e considerando-se cumulativa ou alternativamente, a utilização de múltiplos produtos e subprodutos madeireiros e não madeireiros, bem como a utilização de outros bens e serviços de natureza florestal consta do Art. 25, parágrafo único do decreto $8.188 / 2006$ [2].

Estes sistemas utilizam as melhores técnicas de exploração disponíveis, visando reduzir os danos da floresta, o desgaste do solo, erosão, além de proteger as bacias hidrográficas, atenuar o risco de incêndios e permitem a manutenção da regeneração natural e proteção da diversidade biológica.
O potencial econômico madeireiro das espécies é mensurado a partir de estimadores volumétricos. A estimativa do volume de madeira de florestas nativas normalmente é realizada por meio de inventário florestal, utilizando-se um conjunto de dados como base para se realizar inferências sobre as variáveis de altura, volume e número de árvores por hectare [3].

A regressão pode ser amplamente utilizada nas estimativas e prognoses da produção madeireira, constituindo um procedimento eficiente [4], [5]. Para a estimativa do volume de árvores, é comum o emprego de modelos de regressão com as expectativas de altura [6]. Porém, recentemente, vem sendo estudada a utilização de Redes Neurais Artificiais (RNA) para a estimação dessas variáveis, e foram encontrados resultados satisfatórios de sua aplicação, muitas vezes até superiores [7].

O uso de ferramentas de inteligência artificial na modelagem de crescimento e produção ainda é um assunto novo e pouco explorado no Brasil. Em Ciência Florestal, diversos tópicos podem ser potencialmente tratados por RNAs, entre eles a modelagem do volume de árvores, relações hipsométricas e equações de taper, obtendo resultados expressivos [8], [9], [10]. As RNAs, por outro lado, são aproximadores universais que aprendem com os dados, considerando que os dados falam por si e, têm apresentado excelentes resultados na solução de problemas nas mais diversas áreas do conhecimento humano, principalmente na solução de problemas em ambientes mapeados por variáveis de domínios imprecisos, como no caso do problema da determinação do volume comercial de espécies florestais [11], [12].

Diante do exposto, esta pesquisa tem como objetivo estimar o volume de madeira de espécies nativas provenientes de PMF com o uso de redes neurais artificiais comparando com método de regressão linear na estimativa de volume.

\section{Material e métodos}

O estudo foi realiza na unidade de Manejo Florestal, na fazenda Uberlândia-PA, localizada na Gleba Joana Perez I, entre os municípios de Bagre, Portel, Baião e Oeiras no Estado do Pará. Essa Unidade de Manejo Florestal (UMF I) possui uma área de $45.657,5$ hectares, e está localizada entre os municípios de Santarém e Juruti, Estado do Pará, onde em 2012 iniciou-se sua produção no mês de junho, sendo manejada uma área de 3.000 hectares, que foi certificada com o selo FSC no dia primeiro de outubro do mesmo ano. 
Segundo a classificação de Köppen a região apresenta clima tropical úmido (Amw), caracterizado por apresentar chuvas do tipo monção, isto é, quando apesar de oferecer uma estação seca de pequena duração, possui umidade suficiente para alimentar a floresta tropical. Mantém elevados índices pluviométricos (cerca de $2.400 \mathrm{~mm}$ de chuva), alta temperatura média do $\operatorname{ar}\left(26^{\circ} \mathrm{C}\right)$, e umidade relativa superior a $85 \%$ [13].

A vegetação do estado do Pará é predominantemente composta pela Floresta Amazônica (floresta tropical pluvial). Em mata de terra firme são encontradas as castanheiras, enquanto em áreas de mata de várzea, encontram-se as seringueiras. Na llha do Marajó e nas várzeas de alguns rios são encontrados campos limpos e ao longo do litoral são mangues.

\section{Cubagem Rigorosa}

O método utilizado para a cubagem rigorosa foi o de Smalian. Foi realizado o planejamento para a que a coleta de dados abrangesse a variabilidade das espécies, circunferências e alturas das árvores comerciais presentes na área da floresta estudada.

A seleção das árvores para a cubagem foi realizada a partir da distribuição da frequência diamétrica. Foi feita a seleção e a cubagem rigorosa de árvores-amostra abatidas com DAP $\geq 45 \mathrm{~cm}$ de forma a contemplar toda a distribuição diamétrica encontrada na área inventariada.

Foram cubadas 864 árvores (pois estas foram autorizadas para exploração) na determinação do volume rigoroso utilizando a metodologia de Smalian, que indica que o volume de cada seção foi somado para obter o volume total das toras de acordo com a equação 1

$$
v=v_{0}+\sum_{i=1}^{n} v_{i}+v_{c}
$$

Em que: $v=$ volume, $v_{-}(0)=$ volume do toco, $v_{-} i=$ volume das secções transversais e v_c= volume do cone.

Os dados destas árvores serviram de base para o ajuste dos modelos de volume relacionados na Tabela 1. Os modelos de volume testados foram selecionados na literatura existente sobre o tema, sendo uns dos mais utilizados na área [14].

Das 864 árvores cubadas, foram selecionadas 120 (divididas entre as diferentes classes de diâmetro) para a validação das equações testadas, permanecendo 744 árvores para montar a matriz de variáveis e encontrar o melhor modelo estatístico.

As 120 árvores usadas para validação foram selecionadas aleatoriamente dentro de todas as classes diamétricas
Tabela 1. Modelos matemáticos testados para determinação do volume individual.

Table 1. Mathematical models tested for individual volume determination.

\begin{tabular}{ll} 
No. & Modelo de regressão \\
\hline 1 & $V=B_{0}+B_{1}{ }^{*}$ dap \\
2 & $V=B_{0}+B_{1}{ }^{*} \log ($ dap $)+B_{2}{ }^{*}$ dap \\
3 & $V=B_{0}+B_{1}{ }^{*}$ dap $2 \mathrm{~h}$ \\
5 & $V=B_{0}+B_{1}{ }^{*}(1 /$ dap $)$ \\
6 & $V=B_{0}+B_{1}{ }^{*}(1 /$ dap $)+B_{2}{ }^{*}$ dap \\
7 & $V=B_{0}+B_{1}{ }^{*} \log ($ dap $)+B_{2}{ }^{*} 1 /$ dap \\
8 & $V=B_{0}+B_{1} \log \left(\right.$ dap $\left.{ }^{2}\right)+B_{2}{ }^{*} \log (\mathrm{h})$ \\
\hline 9 & $V=B_{0}+B_{1}{ }^{*} \log \left(\text { dap }^{2}\right)^{*} h$ \\
\hline
\end{tabular}

Em que: $V=$ volume em $\mathrm{m}^{3} ; \beta_{0}, B_{1}, B_{2}=$ coeficientes da regressão, dap = diâmetro a altura do peito em centímetros, $\mathrm{h}=$ altura comercial em metros.

Where: $V=$ volume in $\mathrm{m}^{3} ; \beta_{0}, B_{1}, B_{2}=$ regression coefficients, dap = diameter at breast height in centimeters, $h=$ commercial height in meters.

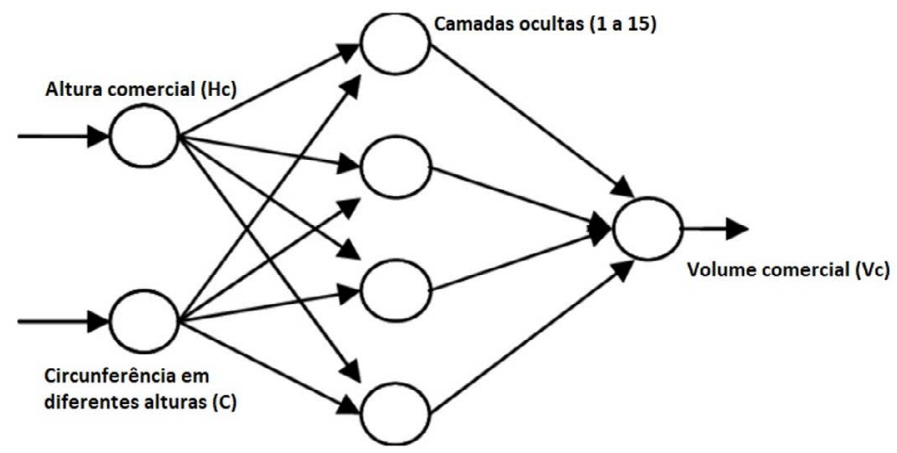

Figura 1. Arquitetura da rede neural artificial testada.

Figure 1. Tested artificial neural network architecture.

de acordo com a frequência das classes, tendo maior frequência nas primeiras classes diamétricas pelo fato de ser uma área nativa, sendo assim, a seleção ficou distribuída da seguinte forma: De 50 a $59,9 \mathrm{~cm}: 20$ árvores; De 60 a 69,9 cm: 20 árvores; De 70 a 79,9 cm: 20 árvores; De 80 a 89,9 cm: 15 árvores; De 90 a 99,9 cm: 15 árvores; De 100 a 109,9 cm: 15 árvores; De 110 a 119,9 cm: 10 árvores; > $120 \mathrm{~cm}$ : 5 árvores.

\section{Modelos de Regressão e Redes Neurais Artificiais}

Os modelos de regressão foram ajustados a partir da análise de correlação entre as variáveis mensuradas na 
floresta. Já as configurações de RNA testadas variaram em relação ao número de neurônios na camada oculta. Os testes foram realizados utilizando o sistema Neuro 4.0, e as estatísticas analisadas foram: Coeficiente de correlação, Raiz quadrática média do erro (RQME), Soma dos Quadrados Residuais (SQR), variância média e análise gráfica de resíduos.

A estimação do volume comercial de árvores pode ser feita por meio de diversas configurações de RNA, foi utilizado o algoritmo de aprendizagem Resilient Propagation, proposto por [15], como alternativa mais eficiente e recomendada para RNA do tipo Multilayer Perceptron com o número de neurônios ocultos variando entre 01 e 15 (totalizando 300 redes treinadas). A função de ativação foi sigmoide com três mil ciclos como critério de parada. Utilizou-se $70 \%$ dos dados para treinamento e 30 \% para validação, separados de forma aleatória.

A figura 1 demonstra o esquema utilizado para treinamento das redes neurais, sendo que na camada de entrada estão inseridas 20 variáveis, sendo elas: altura comercial (hc) e a circunferência em 19 diferentes alturas do fuste. Nas camadas ocultas ou intermediárias variaram a quantidade de neurônios em cada uma (de 1 a 15). E na camada de saída temos a variável desejada, o volume comercial (VC).

Os critérios escolhidos para comparação entre a técnica de regressão e redes neurais artificiais, na estimativa do volume, foram: Erro médio Absoluto (EM) (equação 2), e erro padrão residual (Syx) (equação 3) e análise gráfica dos resíduos [16]. Sendo descritos pelas fórmulas:

$$
\begin{aligned}
& E M=\sum_{i=1}^{n}\left[\frac{V T C-\widehat{V_{T C}}}{n}\right] \\
& S_{\widehat{V_{T C}}}=\sqrt{\sum_{i=1}^{n} \frac{\left(V_{T C}-\widehat{V}_{T C}\right)}{n}}
\end{aligned}
$$

Em que: $E M=$ erro médio absoluto; $V_{\mathrm{TC}}=$ volume total observado; $\mathrm{V}_{\mathrm{TC}}=$ volume total estimado; $\mathrm{n}=$ número de observações; $\mathrm{S}_{(\mathrm{VTC})}$ erro padrão residual.

Where: $\mathrm{EM}=$ absolute mean error; $\mathrm{V}_{\mathrm{TC}}=$ total observed volume; $\mathrm{V}_{\mathrm{TC}}=$ estimated total volume; $\mathrm{n}=$ number of observations; $\mathrm{S}_{(\mathrm{VTC})}$ residual standard error.
Tabela 2. Espécies nativas utilizadas para treinamento das RNAs e ajuste de modelos de regressão.

Table 2. Native species used for RNA training and regression model adjustment.

\section{Espécie}

Acosmium nitens (Vogel) Yakovlev

Astronium lecointei Ducke

Bagassa guianensis Aubl.

Bowdichia nitida Spruce ex Benth.

Buchenavia capitata (Vahl) Eichler

Buchenavia parvifolia Ducke

Buchenavia tetraphylla (Aubl.) R.A.Howard

Caraipa grandiflora Mart.

Caryocar glabrum (Aubl.) Willd.

Caryocar villosum (Aubl.) Pers.

Cedrus libani A. Rich

Cordia goeldiana Huber

Couepia bracteosa Benth.

Couratari guianensis Aubl.

Dinizia excelsa Ducke

Diplotropis nitida Benth.

Dipteryx odorata (Aubl.) Willd.

Enterolobium glaziovii (Benth.) Mesquita

Goupia glabra Aubl.

Hymenaea courbaril L.

Hymenolobium petraeum Ducke

Lecythis pisonis Cambess.

Licaria cannella Kurz

Manilkara huberi (Ducke) Chev.

Mezilaurus itauba (Meisn.) Taub. ex Mez

Micropholis venulosa (Mart. \& Eichler) Pierre

Pseudopiptadenia psilostachya G.P.Lewis \& M.P.Lima

Ocotea cymbarum Kunth.

Ocotea glomerata (Nees) Mez

Ocotea canaliculata (Rich.) Mez

Ormosia excelsa Benth.

Parahancornia amapa (Huber) Ducke.

Platymiscium ulei (Jacq.) Dugand

Pouteria guianensis Aubl.

Pouteria pachycarpa Pires.

Ocotea baturinsis Vattimo

Sacoglottis guianensis Ducke

Tetragastris panamensis (Engl.) Kuntze

Vouacapoua americana Aubl.

Zollernia paraenses Huber 


\section{Resultados e discussões}

As 864 árvores cubadas correspondem à 40 espécies nativas da região amazônica da região de Portel, no estado do Pará. As espécies foram identificadas e podem ser observadas na tabela 2.

As estatísticas descritivas (Tabela 3) apresentam grande variabilidade, principalmente dos volumes, refletindo uma característica de florestas nativas. A curtose indica curva leptocurtica e a assimetria positiva para DAP e volume e negativa para $\mathrm{H}$ comercial indicando que existe um grande número de árvores concentradas nas menores alturas. A dispersão dos dados das variáveis $\mathrm{H}$ comercial, DAP e volume são considerados altos (CV\%>20), indicando elevada variação que é o esperado para áreas nativas [17].

A tabela 4 apresenta os modelos matemáticos ajustados e parâmetros estatísticos utilizados para a escolha do mais adequado.

Tabela 3. Estatística descritiva das variáveis analisadas.

Table 3. Descriptive statistics of the analyzed variables.

\begin{tabular}{|c|c|c|c|}
\hline & Altura (m) & $\mathrm{DAP}(\mathrm{cm})$ & Volume $\left(\mathrm{m}^{3}\right)$ \\
\hline Média & 20,07 & 85,68 & 11,67 \\
\hline Erro padrão & 0,16 & 0,79 & 0,27 \\
\hline Mediana & 20,10 & 81,17 & 9,50 \\
\hline Modo & 20,00 & 63,66 & 13,01 \\
\hline Desvio padrão & 4,74 & 23,35 & 8,03 \\
\hline Variância da amostra & 22,42 & 545,05 & 64,56 \\
\hline Curtose & 0,58 & 1,21 & 7,45 \\
\hline Assimetria & $-0,11$ & 1,05 & 2,22 \\
\hline Intervalo & 28,20 & 145,15 & 63,77 \\
\hline Mínimo & 8,00 & 42,65 & 1,50 \\
\hline Máximo & 36,20 & 187,80 & 65,27 \\
\hline Soma & 17340,91 & 74025,83 & 10082,04 \\
\hline Contagem & 864,00 & 864,00 & 864,00 \\
\hline Nível de confiança (95,0 \%) & 0,3161 & 1,558 & 0,536 \\
\hline
\end{tabular}

Tabela 4. Modelos matemáticos ajustados para as 40 espécies nativas em Portel - PA.

Table 4. Adjusted mathematical models for the 40 native species in Portel - PA.

\begin{tabular}{|c|c|c|c|c|}
\hline $\mathrm{N}^{\circ}$ & Modelos matemáticos & $\mathrm{R}^{2}$ aj (\%) & CV (\%) & Syx \\
\hline 1 & $V=-14,191+0,30037$ *dap & 85,51 & 0,92 & 3,056 \\
\hline 2 & $V=-3,841+2,611^{\star} \log ($ dap$)-0,00209{ }^{*}$ dap & 88,20 & 12,47 & 12,309 \\
\hline 3 & $V=0,675+0,000067^{*}$ dap $^{2} \mathrm{H}$ & 91,29 & 0,62 & 2,061 \\
\hline 4 & $V=36,737-2037,5^{\star} 1 /$ dap & 72,47 & 1,23 & 4,018 \\
\hline 5 & $V=-40,48+1117^{*} /$ dap $+0,4459 *$ dap & 87,17 & 0,88 & 2,917 \\
\hline 6 & $V=-381,6+177,17^{*} \log ($ dap$)+4284 * 1 /$ dap & 86,69 & 0,90 & 3,166 \\
\hline 7 & $V=-112,41+28,337^{*} \log \left(\right.$ dap $\left.^{2}\right)+11,67{ }^{*} \log (\mathrm{h})$ & 82,69 & 0,92 & 2,996 \\
\hline 8 & $V=-114,57+24,542^{*} \log \left(\text { dap }^{2}\right)^{*} h$ & 79,31 & 1,10 & 3,516 \\
\hline 9 & $V=-19,060+0,28608^{*}$ dap $+0,2999^{*} h$ & 88,55 & 0,71 & 2,324 \\
\hline
\end{tabular}

Onde: $\mathrm{R}^{2} \mathrm{aj}$ = coeficiente de determinação ajustado em porcentagem; Syx = erro padrão residual; CV (\%) = coeficiente de variação em porcentagem. Where: $\mathrm{R}^{2} \mathrm{aj}=$ adjusted coefficient of determination in percentage; Syx = residual standard error; CV $(\%)=$ coefficient of variation in percentage. 


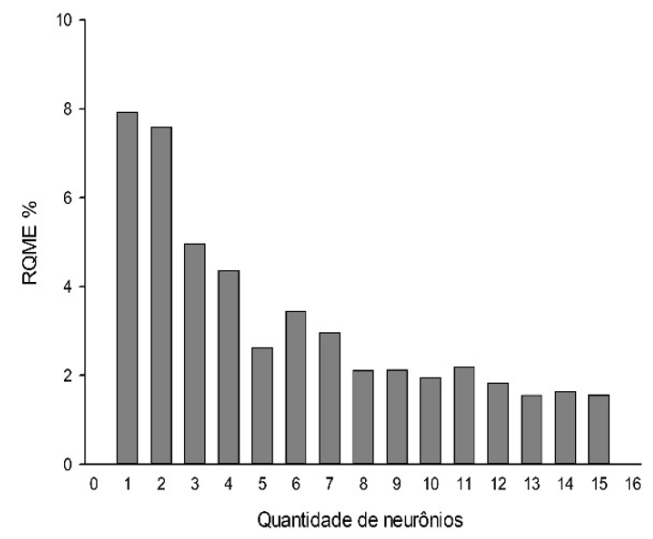

RQME

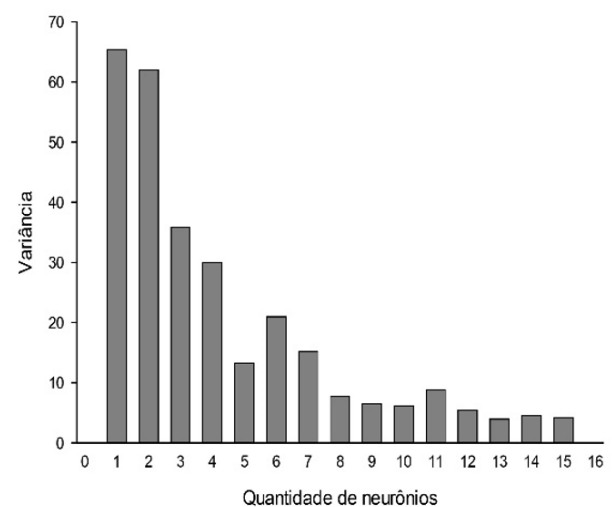

Variância

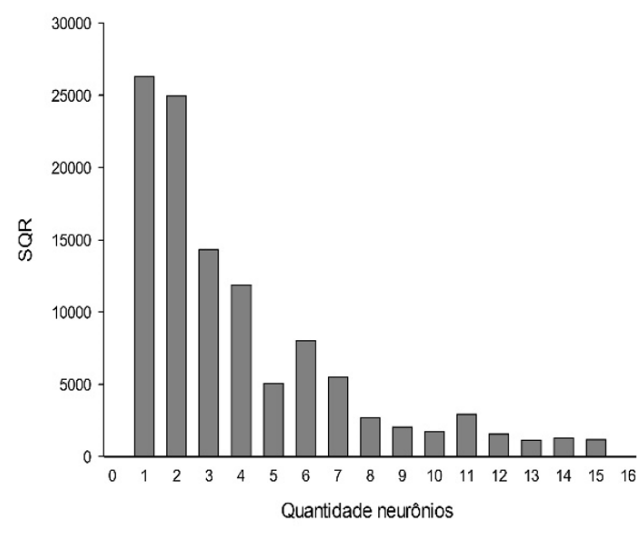

SQR

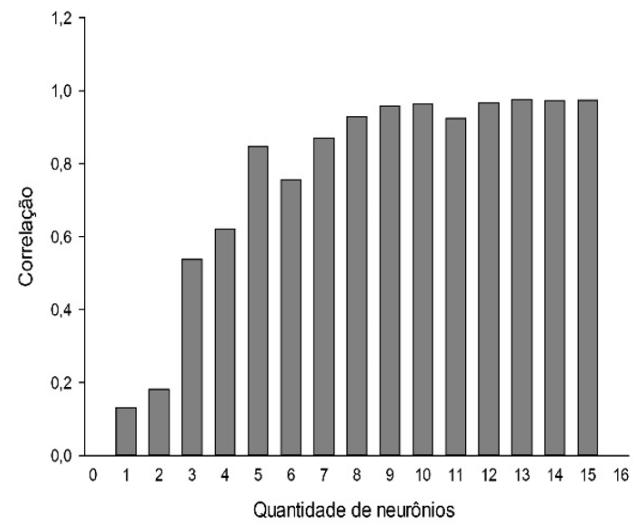

Correlação

Figura 2. Estatísticas para as diferentes quantidades de neurônios na camada intermediária das redes.

Figure 2. Statistics for the different amounts of neurons in the middle layer of the networks.

Tabela 5. Valores médios encontrados para as 20 redes treinadas para cada quantidade de neurônios na camada intermediária.

Table 5. Average values found for the 20 trained networks for each quantity of neurons in the intermediate layer.

\begin{tabular}{|ccccc|}
\hline Neurônios & RQME\% & Sariância & Correlação \\
\hline 1 & 7,93 & 65,35 & 26326,75 & 0,13 \\
\hline 2 & 7,59 & 61,97 & 24963,95 & 0,18 \\
\hline 3 & 4,96 & 35,93 & 14349,47 & 0,54 \\
\hline 4 & 4,36 & 29,96 & 11888,14 & 0,62 \\
\hline 5 & 2,62 & 13,30 & 5062,77 & 0,85 \\
\hline 6 & 3,44 & 21,01 & 8042,43 & 0,76 \\
\hline 8 & 2,95 & 15,18 & 5506,64 & 0,87 \\
\hline 9 & 2,11 & 7,74 & 2705,00 & 0,93 \\
\hline 11 & 2,12 & 6,54 & 2055,80 & 0,96 \\
\hline 12 & 1,95 & 6,13 & 1757,76 & 0,96 \\
\hline 14 & 2,19 & 8,84 & 2942,01 & 0,92 \\
\hline 15 & 1,83 & 5,50 & 1562,59 & 0,97 \\
\hline
\end{tabular}


Como mostrado na tabela 4, o modelo 3 (Spurr) foi - que apresentou melhor ajuste aos dados, com valores de $R^{2}$ aj de 91,29; CV\% de 0,62 e Syx de 2,061. Valores semelhantes foram encontrados por [18], que encontraram R ${ }^{2}$ aj de 0,96; CV\% de 10,3 e Syx de 9,9; ao ajustarem modelos volumétricos para a espécie Calophyllum brasiliense no sul do Tocantins.

Como critério de parada do algoritmo de treinamento utilizou-se o número total de ciclos igual a 3.000 ou erro médio inferior a $1 \%$, conforme sugerido por [19]. Portanto, finalizou-se o treinamento quando um dos critérios foi atingido e a melhor rede para estimar o volume foi selecionada. Para o treinamento das redes neurais artificiais utilizou-se o software Neuro 4.

A figura 2 apresenta os valores de RQME\%, variância, SQR e correlação, onde pôde-se notar uma estabilização quando se atinge 12 neurônios na camada intermediária.

Pelos ensaios realizados com RNAs, foi constatado que a melhor estimação do volume foi obtida utilizando uma RNA multicamada com quinze neurônios na camada intermediária (tabela 5).

Entre as 20 redes treinadas com 15 neurônios na camada intermediária, a rede 299 foi a que apresentou melhores parâmetros para estimativa de volume comercial para as 40 espécies nativas, apresentando a estatística mostrada na tabela 6 .

O erro médio absoluto obtido pela RNA 299 (melhor rede entre as 300 redes testadas), foi de 0,0652; aproximadamente $65 \%$ menor quando comparado com o obtido pelo modelo $3\left(\mathrm{~S}_{\text {purr }}\right)$ com erro médio absoluto de 0,1853. A RNA 299 ainda apresentou um erro padrão residual $\left(S_{y x}\right)$ de 0,2553 , valor $39 \%$ inferior ao encontrado pelo modelo 3 (0,4304), a correlação encontrada para o modelo 3 (Spurr) foi de 0,963, inferior ao valor encontrado para a rede 299 , como mostrado na tabela 5 , comprovando com base nas estatísticas de ajuste a sua superioridade em estimar volumes de árvores individuais nesse estudo.

Amorim [20] ao comparar o método de regressão tradicional e redes neurais artificiais para estimar o volume de espécies nativas na Bahia encontrou valores de $R^{2}$ aj igual a 0,879 para o modelo de Spurr, e ao usar redes neurais artificiais encontrou correlação entre 0,88 e 0,99; e RQME entre $10 \%$ e $23 \%$.

A figura 3 demonstra o histograma de distribuição de classes volumétricas observadas e estimadas pela RNA 299 e modelo 3 (Spurr), onde é possível constatar as boas estimativas de ambos os métodos.

Na tabela 7 podemos comparar os valores do erro médio absoluto, relativo e erro padrão residual.
Tabela 6. Parâmetros estatísticos para treinamento e validação da rede 299 com 15 neurônios na camada intermediária para estimativa de volume comercial de 40 espécies nativas na região de Portel - PA.

Table 6. Statistical parameters for 299 network training and validation with 15 intermediate layer neurons to estimate commercial volume of 40 native species in the Portel - PA region.

\begin{tabular}{|lllll|}
\hline & RQME & Variância & SQR & Correlação \\
\hline Treinamento & 0,2299 & 0,0529 & 31,2393 & 0,9995 \\
Validação & 1,6968 & 2,8477 & 786,0310 & 0,9825 \\
\hline
\end{tabular}

Tabela 7. Determinação dos erros para cálculo do volume.

Table 7. Determination of errors for volume calculation.

\begin{tabular}{|ccc|}
\hline Volume $\left(\mathrm{m}^{3}\right)$ & RNA 299 & Spurr \\
\hline Média & 11,7331 & 11,6690 \\
\hline EM & 0,0652 & 0,1853 \\
\hline EMR\% & 0,5586 & 1,5877 \\
\hline Syx & 0,2553 & 0,4304 \\
\hline R & 0,9985 & 0,9994 \\
\hline
\end{tabular}

Em que: $E M$ = erro médio absoluto; $E M R$ = erro médio relativo; Syx = erro padrão residual; $r=$ coeficiente de correlação.

Where: $E M=$ absolute mean error; EMR = relative mean error; Syx = residual standard error; $r=$ correlation coefficient.
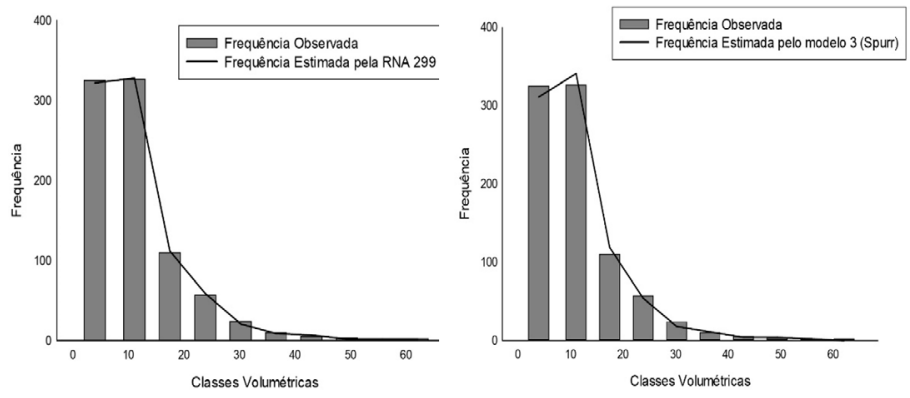

Figura 3. Histograma da distribuição volumétrica para a RNA 299 e Modelo 3.

Figure 3. Histogram of volumetric distribution for RNA 299 and Model 3.

Pelos ensaios realizados com RNAs, foi constatado que a melhor estimação do volume foi obtida utilizando uma RNA multicamada direta, com quinze neurônios na camada intermediária. O erro médio absoluto obtido pela RNA 299 (melhor rede entre as testadas), foi de 0,0652, aproximadamente $65 \%$ menor quando comparado com o obtido pelo modelo de regressão de Spurr com erro médio absoluto de 0,1853. A RNA 299 ainda apresentou um erro padrão residual $\left(S_{y x}\right)$ de 0,2553 , valor $39 \%$ 


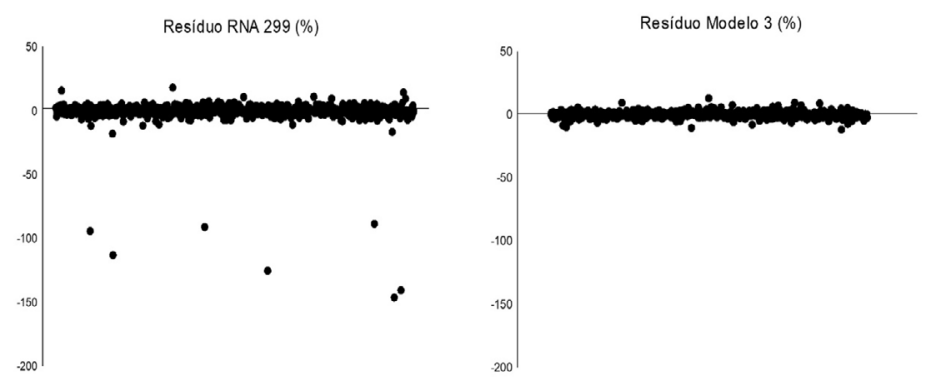

Figura 4. Análise gráfica de resíduos da modelagem volumétrica determinada pelas redes neurais artificiais e modelo de regressão.

Figure 4. Graphical analysis of residuals from volumetric modeling determined by artificial neural networks and regression model.
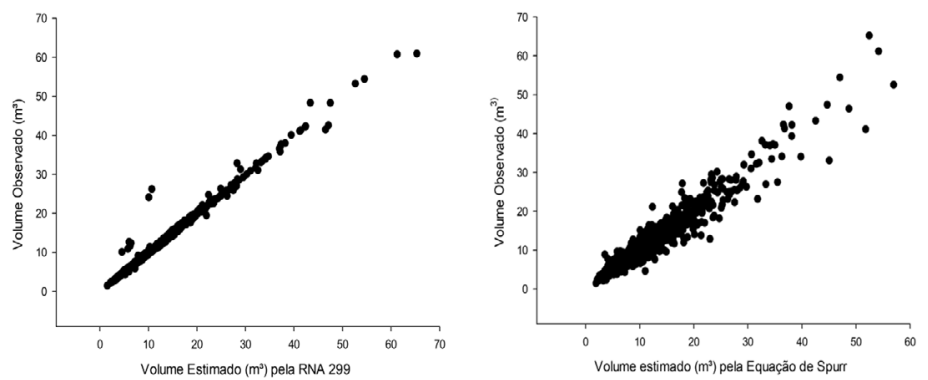

Figura 5. Gráfico de regressão da RNA 299 e modelo de regressão 3.

Figure 5. RNA 299 regression graph and regression model 3.

inferior ao encontrado pela regressão de Spurr $(0,4304)$, comprovando com base nas estatísticas de ajuste a sua superioridade em estimar volumes de árvores individuais nesse estudo. A distribuição volumétrica para a equação de Spurr apresentou uma subestimação para a primeira classe volumétrica $\left(7,87 \mathrm{~m}^{3}\right)$ e superestimação na segunda classe $\left(14,25 \mathrm{~m}^{3}\right)$ e terceira classe $\left(20,62 \mathrm{~m}^{3}\right)$.

A estimativa das classes volumétricas feita pela RNA 299 foi bastante precisa, como demonstrado na figura 3 , não apresentando nenhuma tendência de superou subestimação, já o modelo 3 apresentou uma pequena subestimação na primeira classe e uma superestimação na segunda classe volumétrica.

O valor residual médio para a RNA 299 foi de $0,1174 \mathrm{~m}^{3}$ por árvore, já o modelo 3 obteve um resíduo de 0,2504 $\mathrm{m}^{3}$ por árvore. Assim como no ajuste, a RNA apresentouse mais eficaz na estimativa do volume, embora os resíduos do modelo 3 se apresentem de forma mais compacta, não apresentando nenhum ponto crítico de tendência no decorrer da distribuição, como mostrado na figura 4. Assim como no ajuste, a equação advinda de redes neurais apresentou-se mais eficaz na estimativa do volume, embora os resíduos do modelo estatístico apresentar resíduos melhor distribuídos e de forma mais compacta, não apresentando nenhum ponto crítico de tendência no decorrer de toda a linha de regressão. Por vez, a equação de regressão melhorou sua distribuição residual quando comparada com os resíduos do ajuste, no entanto, resultados estatísticos inferiores a RNA se mantêm. A avaliação da distribuição é importante para que o processo de estimação mantenha a mesma distribuição dos dados observados, evitando-se, assim, distorções e alterações no comportamento da variável original.

A análise gráfica e estatística utilizada mostrou que todos os modelos apresentaram resultados sem tendenciosidade e livre de bias.

A figura 5 apresenta o gráfico de regressão entre os valores observados e estimados pela RNA 299 e o modelo 3 , mostrando a boa qualidade de ajuste dos dois métodos propostos, e evidenciando a superioridade de ajuste das redes neurais artificiais.

As técnicas de inteligência artificial apresentaram coeficientes de correlação superior ao modelo de Spurr, contudo tal diferença não se apresenta significativa para os dados em questão. Deve-se considerar o fato de utilização dessas técnicas para problemas maiores e mais complexos, onde essa diferença pode ser significativa.

\section{Conclusão}

O melhor modelo ajustado foi o modelo 3 (Spurr), que apresentou a melhor estatística na estimativa do volume para as 40 espécies testadas, já a melhor rede foi a 299 configurada com 15 neurônios na camada intermediária e função de ativação sigmoide.

Embora ambas as técnicas sejam consistentes, o desempenho das RNAs na predição volumétrica das espécies nativas apresentou critérios estatísticos superiores aos advindos do modelo 3 (Spurr) através da regressão tradicional, apresentando melhor adequação aos dados e melhor predição da variável desejada.

As redes neurais artificiais multicamada direta, podem ser uma excelente alternativa para a estimação do volume comercial de espécies florestais e, podem contribuir sobremaneira para a eficácia da solução desse importante problema. 


\section{Referências}

[1] I. B. d. G. e. Estadística, Acre: productos da extracao vegetal e silvicultura., 2019.

[2] A. N. P.A.N, Manual Florestal Comunitário na Amazonia Brasileira: Situacao Atual, Desafios e Perspectivas, Brasília: Instituto Internacional de Educacao do Brasil IIEB, 2002.

[3] S. Machado, J. Mello y D. Barros, «Comparacao entre métodos para avaliacao de volume total de madeira por unidade de área, para o pinheiro do Paraná, na regiao sul do Brasil,» Cerne Lavras, vol. 6, n² 2, pp. 55-66, 2000.

[4] O. Santana y E. J.I., «Equacoes volumétircas para uma plantacao de Eucalyptus urophylla destinada a producao de lenha,» de Simpósio Latinoamericano sobre manejo forestal, Santa Maria, 2004.

[5] S. Machado, M. Conceicao y D. Figueiredo, «Modelagem do volume individual para diferentes idades e regimes de desbaste em plantacoes de Pinus oocarpa.,» Ciencias Exatas e Naturais, vol. 4, n² 2, pp. 185-196, 2002.

[6] J. Campos y H. Leite, Mensuracao florestal: perguntas e respostas, Vicosa, 2013.

[7] M. Binoti, Emprego de redes neurais artificiais em mensuracao e manejo florestal, Vicosa: Tese (Doutorado em Ciencia Florestal), 2012.

[8] M. Binoti, D. Binoti y H. Leite, «Aplicacao de redes neurais artificiais par estimacao de altura de povoamentos equianeos de eucalipto,» Árvore, vol. 37, n 4, pp. 639645, 2013.

[9] D. Binoti, M. Binoti, H. Leite y A. Silva, «Reducao dos custos em inventário de povoamentos equianeos utilizando redes neurais artificiais,» Agrária, vol. 8, pp. 125-129, 2012a.

[10] D. Binoti, M. Binoti, H. Leite, A. Silva y A. Santos, «Modelagem da distribuicao diamétrica em povoamentos de eucalipto submetidos a desbaste utilizando automatos celulares,» Árvore, vol. 36, n 5, pp. 931-939, 2012b.

[11] M. Binoti, Redes neurais artifciais para prognose da producao de povoamentos nao desbastados de eucalipto, Vicosa: Dissertacao Mestrado em Ciencia Florestal, 2010.

[12] H. Leite, M. L. Silva, D. Binoti, L. Fardin y F. Takiwaza, «Estimation of inside-bark diameter and heartwood diameter for Tectona grandis Linn. trees usin artificial neural networks,» European Journal of Forest Research, vol. 130, n² 2, pp. 263-269, 2010.

[13] C. Alvares, J. Stape, P. Sentelhas, G. De Moraes, J. Leonarnod y G. Sparovek, "Koppen's climate classification map for Brazil,» Meteorologische Zeitschrift, vol. 22, $n^{\circ} 6$, pp. 711-728, 2013.

[14] F. Loetsch, F. Zohrer y K. Haller, «Forest Inventory Reinbek: Federal Research Organization for Forestry and Forest Products,» Forest Inventory Section, vol. 2, p. 469, 1973.

[15] M. Riedmiller y H. Braun, «Direct adaptive method for faster back propagation learning: the rporp algorithm,» de Internacional Conference on Neural Networks, IEEE, 1993.

[16] N. Draper y H. Smith, Applied regression analysis, New York: John Wiley \& Son, 1998.
[17] F. Gomes, Curso de estadística experimental, Piracicaba: USP/ESALQ, 1990.

[18] M. Silva, A. Vieira, Y. B. Ataíde, Y. Ramos, M. Coelho, M. Giongo y $\mathrm{M}$. Erpen, «Volume, funcoes probabilísticas e producttividade em plantio de Calophyllum brasiliense no município de Dueré (TO),» Advances in Forestry Science, vol. 6, n², pp. 631-638, 2019.

[19] E. \&. O. A. Silva, Dicas para a configuracao de redes neurais, Rio de Janeiro, 2001.

[20] L. Amorim, Potencial de redes neurais artificiais e regressao na estimativa de volume de espécies nativas, Bahia: Universidade Federal do Reconcavo da Bahia, 2018. 